\title{
Total and free thyroid hormone concentrations after elective surgery
}

\author{
R. W. G. PRESCOTT, P. P. B. YEO, M. J. WATSON, I. D. A. JOHNSTON, \\ J. G. RATCLIFFE, AND D. C. EVERED ${ }^{1}$ \\ From the Departments of Medicine, Surgery, and Clinical Biochemistry, University of Newcastle upon Tyne \\ and the Radioimmunoassay Unit, Department of Biochemistry, Royal Infirmary, Glasgow, UK
}

SUMMARY Changes in thyroid hormone concentration and distribution and plasma cortisol levels have been followed in 11 patients undergoing elective cholocystectomy. A significant rise in total and free thyroxine (T4) and fall in total and free triiodothyronine (T3) were noted after surgery. Reverse T3 concentrations rose substantially, suggesting that peripheral conversion of T4 to T3 is diminished and that there is preferential formation of reverse T3. Serum thyroid stimulating hormone concentrations did not change. There was no direct correlation between the change in cortisol and the change in thyroid hormone or reverse $\mathrm{T} 3$ concentrations.

Marked changes in circulating triiodothyronine (T3) and reverse triiodothyronine (rT3) have been reported in association with acute and chronic illness and after surgery (Carter et al., 1974; Bermudez et al., 1975; Burr et al., 1975; Chopra et al., 1975a; Brandt et al., 1976a; Brandt et al., 1976b; Burger et al., 1976). There is evidence that these changes result from reduced clearance and possibly an increased peripheral production of $\mathrm{rT} 3$ and a reduction in T3 derived from T4 by the peripheral tissues (Burr et al., 1975; Chopra, 1976). It had been suggested that these changes are a result of increased cortisol secretion since similar changes are seen after the administration of large doses of dexamethasone (Duick et al., 1974; Chopra et al., 1975b; Burr et al., 1976) but this hypothesis has been challenged by a recent study (Brandt et al., 1976b). It has also been demonstrated that there is reduced binding of thyroid hormones by the transport proteins after surgery (Brandt et al., 1976b), and earlier studies suggest that this results from a fall in thyroxinebinding prealbumin capacity (Kirby et al., 1973).

The objective of this study was to confirm the change in thyroid hormone concentration after surgery in relation to plasma cortisol levels and to examine the distribution of thyroid hormone

1Present address: Director, The Ciba Foundation, London

Received for publication 3 October 1978 between the bound and free fractions in the serum by direct radioimmunoassay techniques.

\section{Patients and methods}

During admission for elective cholecystectomy 11 women (age 27-67) were studied. None had any other detectable illness and all were clinically and biochemically euthyroid. All had a peroperative cholangiogram carried out using Hypaque ${ }^{(R)} 25 \%$, and it has been shown previously that this compound is excreted rapidly unchanged (McChesney and Hoppe, 1957). The observations of Bürgi et al. (1976) also suggest that alterations of thyroid function will only occur after oral cholecystography. A record of anaesthetic agents, premedication, and drugs used in the postoperative period was kept on each patient. None of the subjects required a blood transfusion.

A venous blood sample was obtained from each patient the day before operation (day 1), the day of operation (day 2), and daily thereafter. Each sample was assayed for total T4 and T3 (Evered et al., 1976), free T4 and T3 (Yeo et al., 1977), rT3 (Ratcliffe et al., 1976), and thyroid stimulating hormone (TSH) (Hall et al., 1971) using specific radioimmunoassays. A thyroid hormone binding test (Thyopac-3 (R), Radiochemical Centre, Amersham) and plasma cortisol estimation (Mattingly, 1962) were also carried out in each sample. Each sample was obtained at the same time each day (1700 hours). 


\section{Results}

TOTAL THYROID HORMONE CONCENTRATIONS Total T4 values rose after surgery by $11 \%$ compared with the preoperative day. The peak value was reached on day 4 , and the value was significantly elevated on days 4-6. Total T3 values fell progressively by $33 \%$, reaching their nadir on day 5 and were

$$
\text { Days }
$$
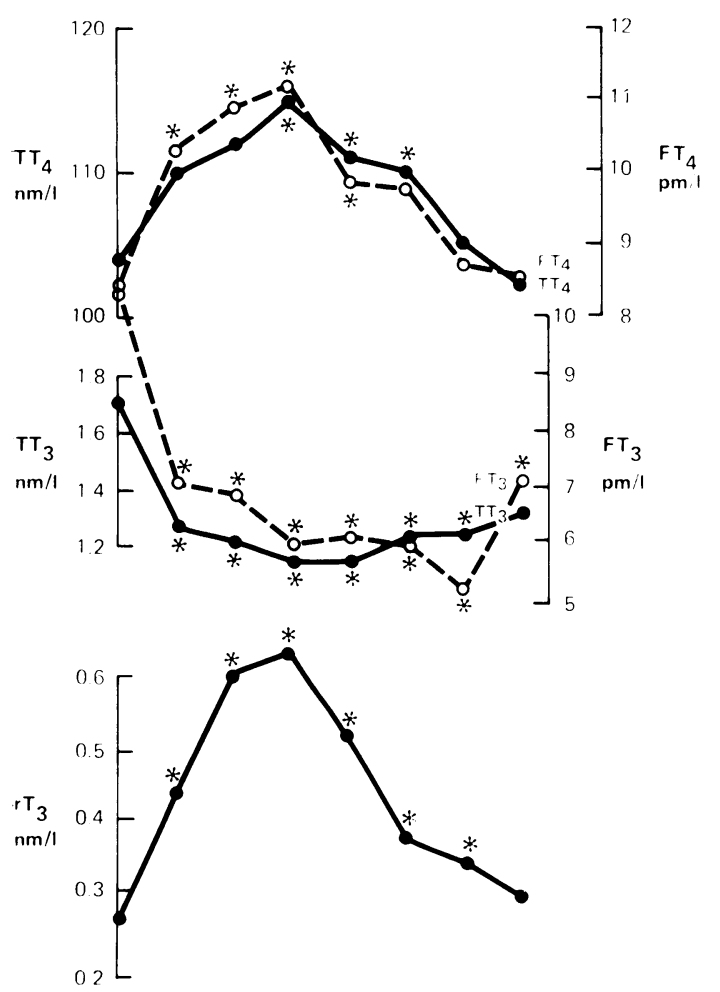

Figure Total and free T4 and T3 levels and reverse T3 after elective surgery. significantly depressed compared with day 1 from days 2 to 7 . These changes are shown in the Figure and Table.

FREE THYROID HORMONE CONCENTRATIONS Free T4 values rose progressively after surgery by $37 \%$ and the peak value was reached on day 4 . The values were significantly elevated compared with day 1 from days 2 to 5 . Free T3 values fell progressively by $51 \%$ after surgery. The nadir was reached on day 7 , but marked and significantly reduced levels were noted on all the postoperative days (Figure and Table).

\section{TT 3 CONCENTRATIONS}

rT3 concentrations rose by $137 \%$ after surgery to a peak on day 4 . The level was significantly raised from days 2 to 7 .

\section{TSH CONCENTRATIONS}

Serum TSH concentration did not change during the course of the study, the mean values for each day falling between 1.4 and $2.9 \mathrm{mU} / 1 ; 17 \%$ of observations fell below the lower limit of detection of the assay.

\section{THYROID HORMONE BINDING TEST ( THYOPAC- $3^{(\mathrm{R})}$ )}

The Thyopac- 3 value fell by $9 \%$ on day 3 , reflecting a reduction in residual binding capacity. The Thyopac-3 value was significantly depressed from days 2 to 6 (Figure and Table).

\section{PLASMA CORTISOL ( 11 -HYDROXYCORTICO- STEROID CONCENTRATION)}

Plasma cortisol concentrations rose promptly after surgery, being at their highest level on the day of operation, and declined progressively thereafter (Table). There was no direct correlation between the

Table Total and free thyroid hormone concentrations, $r T 3$, Thyopac- ${ }^{(\mathrm{R})}$, and cortisol after surgery

\begin{tabular}{|c|c|c|c|c|c|c|c|}
\hline Day & $\begin{array}{l}T T 4 \\
(n m / I)\end{array}$ & $\begin{array}{l}F T 4 \\
(\mathrm{pm} / \mathrm{l})\end{array}$ & $\begin{array}{l}T T 3 \\
(n m / 1)\end{array}$ & $\begin{array}{l}\text { FT3 } \\
(p m / 1)\end{array}$ & $\begin{array}{l}r T 3 \\
(n m / I)\end{array}$ & Thyopac-3 & $\begin{array}{l}\text { Cortisol } \\
(\mathrm{mm} / \mathrm{l})\end{array}$ \\
\hline 1 & $104 \pm 5$ & $8.4 \pm 0.5$ & $1 \cdot 70 \pm 0 \cdot 10$ & $10.5 \pm 0.8$ & $0.26 \pm 0.02$ & $117 \pm 3$ & $502 \pm 44$ \\
\hline 2 & $110 \pm 7$ & $10 \cdot 3 \pm 0.7 \ddagger$ & $1 \cdot 27 \pm 0 \cdot 10_{+}^{+}$ & $7 \cdot 1 \pm 1 \cdot 3_{+}^{+}$ & $0.44 \pm 0.06^{*}$ & $111 \pm 3+$ & $1751 \pm 162+$ \\
\hline 3 & $112 \pm 5$ & $10.9 \pm 0.7_{+}^{+}$ & $1 \cdot 22 \pm 0.13_{+}^{+}$ & $6.9 \pm 1 \cdot 3_{+}^{+}$ & $0.60 \pm 0.07_{+}^{+}$ & $107 \pm 2_{+}^{+}$ & $1101 \pm 187+$ \\
\hline 4 & $115 \pm 4+$ & $11 \cdot 2 \pm 0.4_{+}^{+}$ & $1.15+0.08_{+}^{+}$ & $6 \cdot 0 \pm 1 \cdot 0_{+}^{+}$ & $0.63 \pm 0.08_{+}^{+}$ & $109 \pm 2_{+}^{+}$ & $944+119+$ \\
\hline 5 & $111 \pm 4^{*}$ & $9.9 \pm 0.6^{*}$ & $1 \cdot 14 \pm 0.08_{+}^{+}$ & $6 \cdot 2 \pm 1 \cdot 1 \ddagger$ & $0.51 \pm 0.07_{+}^{+}$ & $112 \pm 3^{*}$ & $745 \pm 86+$ \\
\hline 6 & $110 \pm 4^{*}$ & $9.8 \pm 0.8$ & $1 \cdot 23 \pm 0.08_{+}^{+}$ & $6 \cdot 1 \pm 1 \cdot 0^{+}$ & $0.37 \pm 0.05^{*}$ & $112 \pm 2^{*}$ & $687 \pm 51+$ \\
\hline 8 & $102 \pm 3$ & $8.5 \pm 0.7$ & $1.31 \pm 0.15$ & $7 \cdot 1 \pm 1 \cdot 1+$ & $0.29 \pm 0.03$ & $115 \pm 2$ & $779 \pm 74 \dagger$ \\
\hline
\end{tabular}

TT4 = total thyroxine, FT4 = free thyroxine, TT3 = total triiodothyronine, FT3 = free triiodothyronine, rT3 = reverse triiodothyronine All values \pm 1 SEM

${ }^{*} \mathbf{P}<0.05$

$\left.\begin{array}{l}\dagger \mathbf{P}<0.01 \\ \pm \mathbf{P}<0.001\end{array}\right\}$ Compared with day 1 using a paired $t$ test 
change in cortisol and the change in thyroid hormone or $\mathrm{rT} 3$ concentrations.

\section{Discussion}

The marked changes in $\mathrm{T} 3$ and $\mathrm{rT} 3$ concentrations in association with acute and chronic illness and malnutrition and after surgery have been reported by a number of authors (Carter et al., 1974; Bermudez et al., 1975; Burr et al., 1975; Chopra et al., 1975a; Brandt et al., 1976a, b; Burger et al., 1976). These data confirm the findings of other authors with respect to the total hormone concentrations. Recent work (Carter et al., 1976) suggests that the peripheral conversion of $\mathrm{T} 4$ to $\mathrm{T} 3$ is diminished and that increased amounts of the alternative metabolite (rT3) are formed preferentially. There is growing evidence that more than one enzyme is involved and that there are specific deiodinases for inner and outer ring deiodination. The mechanism by which the peripheral production of $\mathrm{T} 3$ is diverted to $\mathrm{rT3}$ remains uncertain. It had been suggested that these changes resulted from an increase in cortisol secretion since similar changes are seen after the administration of large doses of dexamethasone (Duick et al., 1974; Chopra et al., 1975b; Burr et al., 1976). This view was, however, questioned by Brandt et al. (1976b), who showed that these changes in thyroid hormone concentrations occurred in patients undergoing abdominal surgery in whom afferent neurogenic impulses were blocked during and after operation by epidural analgesia-and in whom the stress-induced increase in cortisol was abolished. The absence of any temporal correlation between the changes in cortisol and thyroid hormone concentrations also indicates that these latter changes are not dependent upon a stress-induced increase in cortisol secretion. A number of the metabolic responses to surgical trauma are abolished by blocking afferent neurogenic stimuli from the operative field (including the changes in cortisol, glucose, cyclic-AMP, and growth hormone). Other responses, notably catecholamine release, however, are not abolished, and further study is required to identify the mechanisms involved. The physiological advantages and/or disadvantages of these adaptive changes renain obscure.

The rise in T4 conflicts with earlier reports of a small fall in T4 (Burr et al., 1975) and unchanged PBI concentrations (Kirby et al., 1973) but is consistent with the use in T4 reported by Brandt et al. $(1976 \mathrm{a}, \mathrm{b})$ and the increase in $\mathrm{T} 4$ production rate reported by Harland et al. (1972). Similar rises in T4 after surgery under halothane anaesthesia have also been reported by Oyama and his colleagues $(1969 ; 1972)$. The physiological significance of these changes remains uncertain.

Free T4 and T3 levels showed qualitatively similar changes after surgery when compared with total T4 and T3. It was noted, however, that the amplitude of the free hormone changes was proportionately much greater than those of the total hormones. These changes indicate that the distribution of these hormones is altered by surgical stress, and it might be expected that they would be accompanied by an increased clearance of T4 from the circulation and a reduced clearance of $T 3$. Changes consistent with this view have been reported postoperatively by Harland et al. (1972) for T4 and in sick euthyroid patients by Carter et al. (1976) for T3. The increase in T4 can be largely attributed to a progressive discharge of T4 from the liver (Harland et al., 1974).

Current techniques are inadequate to establish all the factors that contribute to the changes in thyroid hormone concentrations, but changes in $\mathrm{T} 4$ and $\mathrm{T} 3$ production rate, alterations in thyroid hormone binding protein capacity, and alterations in cellular uptake, metabolism, and degradation have all been implicated by various authors. The metabolic factors that initiate these changes and the mechanisms by which they occur remain unclear.

PPBY was supported by the Nuffield Foundation, and this work will form part of a dissertation for the degree of MD to be submitted to the University of Singapore. The support of the Scientific and Research Committee of the Newcastle Area Health Authority (Teaching) is gratefully acknowledged. We are grateful for the technical assistance of Miss $\mathbf{J}$. Marshall and Mrs E. Green.

\section{References}

Bermudez, F., Surks, M. I., and Oppenheimer, J. H. (1975). High incidence of decreased serum triiodothyronine concentration in patients with non-thyroidal disease. Journal of Clinical Endocrinology and Metabolism, 41, 27-40.

Brandt, M., Kehlet, H., Hansen, J. M., and Skovsted, L. (1976a). Serum triiodothyronine and surgery (Letter). Lancet, 1, 491.

Brandt, M. R., Kehlet, H., Skovsted, L., and Hansen, J. M. (1976b). Rapid decrease in plasma-triiodothyronine during surgery and epidural analgesia independent of afferent neurogenic stimuli and of cortisol. Lancet, 2, 1333-1336.

Burger, A., Nicod, P., Suter, P., Vallotton, M. B., Vagenakis, A., and Braverman, L. (1976). Reduced active thyroid hormone levels in acute illness. Lancet, 1, 653-655.

Bürgi, H., Wimpfheimer, C., Burger, A., Zaunbauer, W., Rösler, H., and Lemarchand-Béraud, T. (1976). Changes of circulating thyroxine, triiodothyronine 
and reverse triiodothyronine after radiographic contrast agents. Journal of Ctintical Endocrinology and Metabolism, 43, 1203-1210.

Burr, W. A., Griffiths, R. S., Black, E. G., Hoffenberg, R., Meinhold, H., and Wenzel, K. W. (1975). Serum triiodothyronine and reverse triiodothyronine concentrations after surgical operation. Lancet, 2, 1277 1279.

Burr, W. A., Ramsden, D. B., Griffiths, R. S., Black, E. G., Hoffenberg, R., Meinhold, H., and Wenzel, K. W. (1976). Effect of a single dose of dexamethasone on serum concentrations of thyroid hormones. Lancet, 2, 58-61.

Carter, J. N., Eastman, C. J., Corcoran, J. M., and Lazarus, L. (1974). Effect of severe, chronic illness on thyroid function. Lancet, 2, 971-974.

Carter, J. N., Eastman, C. J., Corcoran, J. M., and Lazarus, L. (1976). Inhibition of conversion of thyroxine to triiodothyronine in patients with severe chronic illness. Clinical Endocrinology, 5, 587-594.

Chopra, I. J. (1976). An assessment of daily production and significance of thyroidal secretion of $3,3^{\prime}, 5^{\prime}$ triiodothyronine (reverse $T_{3}$ ) in man. Journal of Clinical Investigation, 58, 32-40.

Chopra, I. J., Chopra, U., Smith, S. R., Reza, M., and Solomon, D. H. (1975a). Reciprocal changes in serum concentrations of $3,3^{\prime}, 5^{\prime}$, triiodothyronine (reverse $T_{3}$ ) and $3,3^{\prime} 5$ triiodothyronine $\left(\mathrm{T}_{3}\right)$ in systemic illnesses. Journal of Clinical Endocrinology and Metabolism, 41, 1043-1049.

Chopra, I. J., Williams, D. E., Orgiazzi, J., and Solomon, D. H. (1975b). Opposite effects of dexamethasone on serum concentrations of 3, 3'5'-triiodothyronine (reverse $\mathrm{T}_{3}$ ) and 3, 3', 5-triiodothyronine $\left(\mathrm{T}_{3}\right)$. Journal of Clinical Endocrinology and Metabolism, 41, 911-920.

Duick, D. S., Warren, D. W., Nicoloff, J. T., Otis, C. L., and Croxson, M. S. (1974). Effect of single dose dexamethasone on the concentration of serum triiodothyronine in man. Journal of Clinical Endocrinology and Metabolism, 39, 1151-1154.

Evered, D. C., Vice, P. A., Green, E., and Appleton, D. (1976). Assessment of thyroid hormone assays. Journal of Clinical Pathology, 29, 1054-1059.

Hall, R., Amos, J., and Ormstơn, B. J. (1971). Radioimmunoassay of human serum thyrotrophin. British Medical Journal, 1, 582-585.

Harland, W. A., Horton, P. W., Strang, R., Fitzgerald, B., Richards, J. R., and Holloway, K. B. (1974). Release of thyroxine from the liver during anesthesia and surgery. British Journal of Anaesthesia, 46, 818-820.

Harland, W. A., Orr, J. S., and Richards, J. R. (1972). Increased thyroxine secretion following surgical operation. Scottish Medical Journal, 17, 92-97.

Kirby, R., Clark, F., and Johnston, I. D. A. (1973). The effect of surgical operation of moderate severity on thyroid function. Clinical Endocrinology, 2, 89-99.

McChesney, E. W., and Hoppe, J. O. (1957). Studies of the tissue distribution and excretion of sodium diatrizoate in laboratory animals. American Journal of Roentgenology, 78, 137-144.

Mattingly, D. (1962). A simple fluorimetric method for the estimation of free 11-hydroxycorticoids in human plasma. Journal of Clinical Pathology, 15, 374-379.

Oyama, T., Matsuki, A., and Kudo, T. (1972). Effect of halothane, methoxyflurane anaesthesia and surgery on plasma thyroid-stimulating hormone (TSH) levels in man. Anaesthesia, 27, 2-8.

Oyama, T., Shibata, S., Matsuki, A., and Kudo, T. (1969). Serum endogenous thyroxine levels in man during anaesthesia and surgery. British Journal of Anaesthesia, 41, 103-108.

Ratcliffe, W. A., Marshall, J., and Ratcliffe, J. G. (1976). The radioimmunoassay of $3,3^{\prime}, 5^{\prime}$ triiodothyronine (reverse $\mathrm{T}_{3}$ ) in unextracted human serum. Clinical Endocrinology, 5, 631-641.

Yeo, P. P. B., Lewis, M., and Evered, D. C. (1977). Radioimmunoassay of free thyroid hormone concentrations in the investigation of thyroid disease. Clinical Endocrinology, 6, 159-165.

Requests for reprints to: Dr D. C. Evered, Director, The Ciba Foundation for the Promotion of International Cooperation in Medical and Chemical Research, 41 Portland Place, London W1N 4BN, UK 